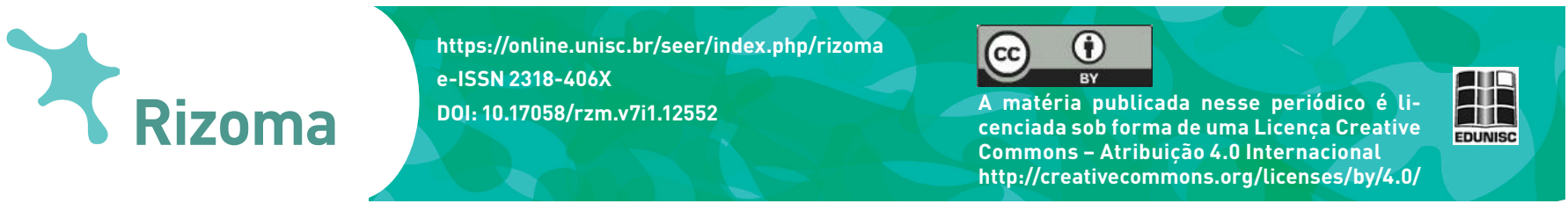 \\ José de San Martín ante la tumba del soldado desconocido:
}

\author{
un análisis de Revolución: el cruce de los Andes
}

Resumen: Este artículo analiza el discurso sobre la memoria colectiva de la independencia argentina propuesto en el filme Revolución: el cruce de los Andes (Leandro Ipiña, 2011), una coproducción argentino-española realizada en las celebraciones del bicentenario. Para ello se enfoca en tres aspectos del largometraje: la representación de José de San Martín, la idea de la masa anónima, transnacional y multiétnica como motor de la emancipación y la centralidad del discurso sobre la libertad.

Palabras clave: Memoria colectiva. Bicentenario. Transnacionalismo. Multietnicidad.

\section{José de San Martín frente à tumba do soldado desconhecido: Uma análise de Revolución: el cruce de los Andes}

Resumo: Este artigo analisa o discurso sobre a memória coletiva da independência argentina proposto no filme Revolución: el cruce de los Andes (Leandro Ipiña, 2011), coprodução argentino-espanhola realizada nas celebrações do bicentenário. Para tanto, focaremos em três aspectos do longa-metragem: a representação de José de San Martín, a ideia da massa anônima, transnacional e multiétnica como motor da emancipação, e a centralidade do discurso sobre a liberdade. Palavras-chave: Memória coletiva. Bicentenário. Transnacionalismo. Multietnicidade.

\section{José de San Martín before the grave of the unknown soldier: An analysis of Revolution: the crossing of the Andes}

Abstract: This paper analyzes the discourse about collective memory of Argentine independence proposed in the movie Revolución: el cruce de
Ignacio Del Valle Davila’

Professor do curso de Cinema e Audiovisual da Universidade Federal da Integração Latino-Americana (Unila) e professor colaborador da pós-graduação em Multimeios da Universidade Estadual de Campinas (Unicamp). Doutor em Cinema e Mestre em Artes do Espetáculo e Mídias, ambos pela Université Toulouse 2 Le Mirail. Graduado em Comunicação Social com habilitação em Jornalismo pela Universidad Católica de Chile. Entre 2015 e 2016 fez pós-doutorado no Programa de Pós-graduação em Multimeios da Unicamp com uma bolsa PNPDCAPES. Entre 2013 e 2015 realizou um pós-doutorado em História na Universidade de São Paulo (USP) com uma bolsa da FAPESP. Entre 2009 e 2011 foi professor substituto (enseignant vacataire) de cinema latinoamericano no Centre Universitaire Jean-François Champollion (Albi, França). Também foi membro do Conselho de Administração do Festival Cinélatino, Rencontres de Toulouse

(ARCALT), onde atuou como um dos programadores de curta-metragens (2009-2013). Desde 2009 faz parte do Comitê Editorial da revista Cinémas d'Amérique Latine (Qualis A2). É autor dos livros Cámaras en trance: el nuevo cine latinoamericano, un proyecto cinematográfico subcontinental (Chile,

2014) e Le Nouveau Cinéma Latinoaméricain (1960-1974) (França, 2015) e co-realizador do documentário

Después de los cisnes (Chile, 2006). Publicou trabalhos acadêmicos no Brasil, França, Canadá, México, Espanha, Argentina e Chile. 

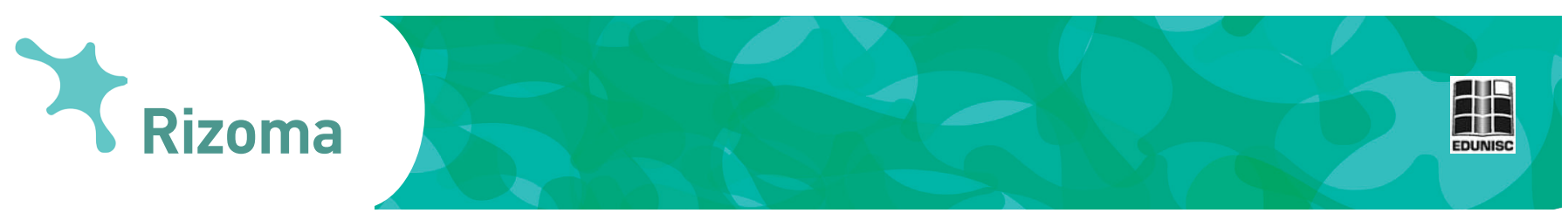

los Andes (Leandro Ipiña, 2011), an Argentine-Spanish co-production realized in the celebrations of the bicentennial. For this, it focuses in three aspects of the feature: the representation of José de San Martín, the idea of an anonymous, transnational and multiethnic mass as the motor of emancipation and the centrality of the discourse of freedom.

Keywords: Collective memory. Bicentennial. Transnationalism. Multiethnicity.

\section{Introducción: Coproducir la independencia}

En la segunda mitad de los años 2000 el productor español Sancho Gracia, director de Lusa Filmes, concibió la realización de una serie de largometrajes, coproducidos con América Latina, sobre los líderes de las independencias latinoamericanas. La serie fílmica, titulada Los Libertadores contaría con la participación de Televisión Española y las productoras Lusa Filmes y Wanda Filmes, por el lado español, y con productores latinoamericanos diferentes para cada uno de los filmes concebidos. Todos los directores serían latinoamericanos.

El proyecto de Los Libertadores se inscribía en los esfuerzos de diplomacia cultural emprendidos por el gobierno del socialista José Luis Rodríguez Zapatero dentro del ámbito de las celebraciones del bicentenario de las independencias latinoamericanas. Originalmente se concibieron ocho filmes sobre José de San Martín, José Martí, Miguel Hidalgo, Artigas, Bernardo O’Higgins, Simón Bolívar, Tupac Amaru y Joaquim José da Silva Xavier, Tiradentes².

En el caso argentino, la coproducción sobre San Martín contó con una amplia participación del gobierno de Cristina Kirchner y de entidades públicas: Radio Televisión Argentina (RTA), Instituto Nacional de Cine y Artes Audiovisuales (INCAA), el portal educativo del Ministerio de Educación (Educ.ar), la emisora educativa pública Canal Encuentro, la Universidad Nacional del General San Martín, la Unidad Ejecutora Bicentenario y el Gobierno de la Provincia de San Juan. El director del filme, Leandro Ipiña, que no había realizado ningún largometraje hasta entonces, trabajaba en el Canal Encuentro.

Los fuertes vínculos con el gobierno de Cristina Kirchner han llevado a que el filme sea asociado a esa tendencia política. Según Tzvi Tal (2015, p. 241): "la reconstrucción de la imagen del personaje histórico difunde el discurso kirchnerista, cuyo portavoz más notorio, luego del fallecimiento de Néstor Kirchner, es la Presidenta en ejercicio Cristina Fernández de Kirchner”. Mi objetivo en este artículo no es ahondar específicamente en el estudio de las relaciones entre el proyecto ideológico del kirchnerismo y el filme, sino que estudiar el tipo de memoria que Revolución: el cruce de los Andes construye 


\section{$\gamma_{\text {Rizoma }}$}

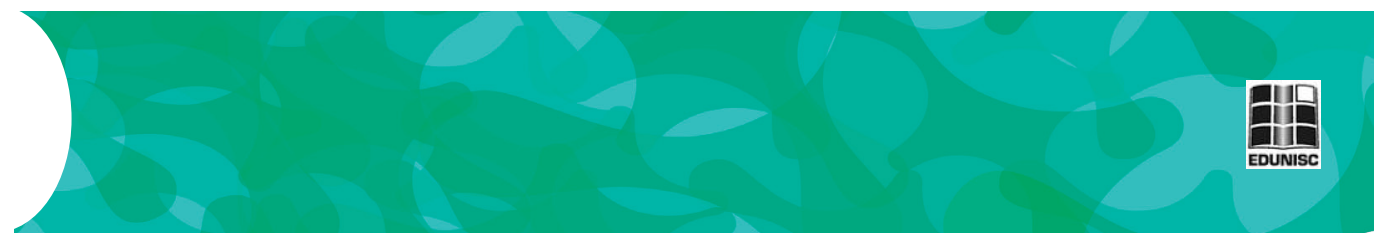

sobre las guerras de independencia, en el marco de las celebraciones del bicentenario.

${ }^{3}$ Uso como fuente de inspiración el estudio de Noël Carroll (2005) sobre los conceptos de ficción, no ficción y aserción presupuesta.

\section{La historia en la historia}

Existe un recurso narrativo tan frecuente en las películas latinoamericanas sobre la independencia que casi llega a ser un lugar común. El filme comienza con una escena situada en el pasado, en la que un personaje se ve obligado a recordar lo que le pasó a él o a rememorar lo que le aconteció a otro personaje en un momento aún más pretérito. A partir de entonces, todo el enredo del filme se desarrolla como un largo racconto, como si su enunciador fuese ese personaje que recuerda y estuviéramos teniendo acceso al relato de su memoria o de la memoria que le ha sido transmitida. Eventualmente la narración puede volver al tiempo presente de ese personaje, aunque eso no siempre suceda, lo que sí pasa es que indefectiblemente al final de la historia el racconto se cierra y ese personaje que "recuerda" concluye su narración. Esa estructura está presente en filmes como Nuestra tierra de paz (Arturo S. Mom, Argentina, 1939), El santo de la espada (Leopoldo Torre Nilsson, Argentina, 1970), Independência ou morte! (Carlos Coimbra, Brasil, 1972), La redota: una historia de Artigas (César Charlone, Uruguay, 2011), Revolución: el cruce de los Andes (Leandro Ipiña, Argentina, 2011), entre otros.

Es como si el filme le propusiera a su público: imaginemos que lo que viene a continuación es la memoria de $\mathrm{X}$ sobre una serie de acontecimientos $^{3}$. Como puede verse se plantea aquí una cuestión relacionada con la focalización que predominará en el filme. Esta cuestión me interesa, para los fines de este artículo, específicamente desde la perspectiva de la memoria que cada filme pretende representar, pues no es lo mismo que el filme le proponga al público ser la memoria de un emperador que la de un soldado raso. En El santo de la espada quien recuerda es el propio San Martín y el filme, realizado en plena dictadura de Onganía, ofrece un relato monolítico y monumental del prócer, bastante a proclive al discurso del régimen. Algo similar sucede con Independência ou morte!, donde es el Emperador D. Pedro I quien parece recordar su pasado justo antes de abdicar; el filme también fue realizado durante una dictadura - el régimen de Emílio Garrastazu Médici - y estrenado durante las celebraciones de los 150 años de la independencia de Brasil. En el caso de La Redota, el ejercicio de rememoración está a cargo del pintor Juan Manuel Blanes, al que le han encomendado un cuadro sobre Artigas y no sabe cómo pintarlo, se puede percibir aquí una estructura de mise en abyme, que sirve para que el filme reflexione sobre su propio ejercicio de representación de 

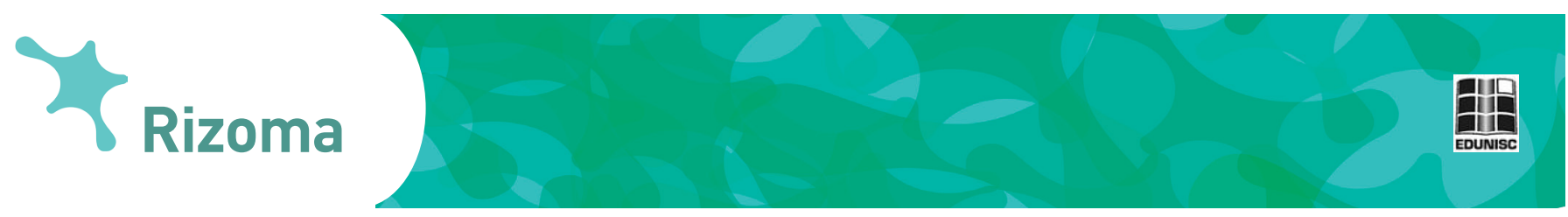

ese héroe nacional. En el caso de Nuestra tierra de paz es un padre quien le cuenta la historia de San Martín a su hija, lo que refuerza la noción de transmisión de la memoria colectiva entre generaciones ${ }^{4}$.

Quien recuerda en Revolución: el cruce de los Andes es el anciano Manuel Corvalán, un soldado que, cuando era adolescente, sirvió como amanuense de San Martín durante el cruce de los Andes y el inicio de la expedición a Chile en 1817. Su relato memorial corresponde a la entrevista que le concede, en 1880, a un periodista con motivo de la repatriación de los restos del prócer. No es aquí el propio héroe quien recuerda, tampoco lo es un célebre pintor, sino que un soldado olvidado, que fue testigo de los actos de San Martín y que participó de forma anónima en la campaña militar. En este último caso, el filme le propone al público imaginar que lo que asistirá es la memoria oral de un soldado pobre y olvidado. Es decir, propone que imagine que estará ante una "memoria popular" ignorado. A partir de aquí cabría preguntarse qué encierra la idea de olvido histórico presente en Revolución: el cruce de los Andes. Dicho de otra manera, ¿qué elementos alternativos a la historia oficial surgen en la "memoria popular" que propone Revolución: el cruce de los Andes? En las próximas páginas analizaré ese ejercicio de revisión histórica.

\section{La revisión de San Martín en perspectiva}

El pasado nacional ha recibido bastante atención por parte del cine argentino prácticamente desde sus inicios (ERAUSQUIN, 2008). Las cintas sobre acontecimientos históricos y sus responsables, así como otras de ambientación histórica vivieron diferentes momentos de auge productivo. A lo largo de la década de 1910, proliferaron las producciones silentes sobre la independencia, asociadas a las celebraciones del centenario. A fines de 1930 y comienzos de 1940, volvió a producirse un incremento de filmes sobre el pasado, que tuvo a la expansión y consolidación del estado-nación en el siglo XIX como principal temática y a la figura del gaucho como emblema. El cine histórico resurge entre 1966 y 1973, fomentado por la dictadura conocida como la Revolución Argentina, preocupada por promover una política cultural nacionalista y católica. Cuarenta años después vuelve a ser incentivado por el gobierno argentino, esta vez con motivo del bicentenario. Curiosamente, la figura de José de San Martín, el principal héroe de la independencia, reconocido por la historia oficial como el "Libertador" del país, ha sido relativamente poco abordada a lo largo de un siglo de cine histórico. Los principales largometrajes que lo tienen como protagonista son: Nuestra tierra de paz (Arturo S. Mom, 1939), El santo de la espada (Leopoldo Torre-Nilsson, 1970),
${ }^{4}$ Sin embargo, el filme presenta la particularidad de que el padre es francés y al comienzo los dos personajes hablan sobre San Martín en esa lengua -la producción de hecho contó con el apoyo de la embajada de Francia y de residentes en Argentina de ese país (ERAUSQUIN, 2008, p. 69). Ese detalle sirve tanto para poner de relieve los vínculos entre el prócer y el país que lo acogió durante su exilio, como para mostrar la integración cultural de los inmigrantes.

${ }^{5}$ Uso las comillas para en claro que esa memoria popular propuesta por el filme es una construcción ficcional. 


\section{$\gamma_{\text {Rizoma }}$}

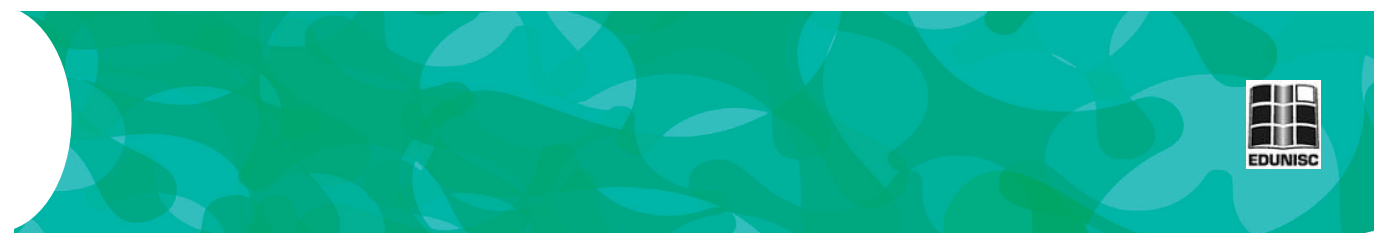

El general y la fiebre ${ }^{6}$ (Jorge Coscia, 1993) y Revolución: el cruce de los Andes (Leandro Ipiña, Argentina, 2011).

De los tres primeros, el Santo de la espada es la fuente audiovisual más importante para la construcción de una iconosfera popular sobre la independencia argentina, en general, y sobre la imagen de San Martín, en particular. Su relevancia para la iconosfera - es decir, para el "conjunto de imagens que, num dado contexto, está socialmente acessível" (MENESES, 2003, p. 15) - viene dada por su enorme éxito entre el público -fue uno de los filmes argentinos más vistos del siglo $\mathrm{XX}-$, al que contribuyeron un elevado presupuesto y una fuerte campaña de promoción en los medios de comunicación de la época. El San Martín de Torre Nilsson, interpretado por Alfredo Alcón, responde a la versión más castrense del héroe y a un esfuerzo de monumentalización acorde con la historia oficial: hierático, lacónico, sentencioso, valiente, decidido, inflexible, sacrificado y arrojado, es generalmente filmado en contra-plongée y resulta tan marmóreo como un monumento ecuestre (DEL VALLE DÁVILA, 2016; ERAUSQUIN, 2008; LUSNICH, 2005).

Esa representación del héroe parece ser la principal referencia audiovisual que revisa Revolución: el cruce de los Andes. Es más, el núcleo dramático del filme de Leandro Ipiña se restringe a un momento muy específico de las campañas militares de San Martín, el cruce de los Andes y la batalla de Chacabuco, que es también el momento histórico que aborda con más detalle el filme de Torre Nilsson? ${ }^{7}$ Por otro lado, en ambos casos se resalta la extrema dificultad de la travesía por las montañas, la crudeza del clima y la fragilidad de la salud de San Martín, elementos contra los que tiene que luchar y de los que debe sobreponerse, y cuya función es ampliar la dimensión heroica del personaje.

Sin embargo, más allá de esos aspectos, poco tienen en común los personajes que interpretaron Alfredo Alcón, en 1970, y Rodrigo de la Serna, en 2010. El San Martín encarnado por De la Serna es más joven - más joven incluso de lo que era el personaje histórico en 1817 - y mucho menos serio, rígido y solemne que el de Alcón. En El santo de la espada, este último interpretó los recurrentes enfados del general frunciendo el ceño y endureciendo la voz, para pronunciar frases sentenciosas y grandilocuentes, es decir, sin salirse nunca de la rigidez que caracteriza al personaje en ese filme. De la Serna hace que los enfados del héroe se transformen en ataques de rabia, gritos y aspavientos, con un San Martín que se tira al suelo, totalmente ofuscado, cuando cree que sus ejércitos llegarán demasiado tarde a Chile o que derriba de una patada, furioso, una mesilla durante la batalla de Chacabuco.

Es evidente que esta segunda caracterización intenta humanizar al héroe, aproximándolo al público y facilitando la identificación con
6 El único que no se enmarca dentro de un momento de crecimiento de la producción de cine histórico.

7 El marco temporal que aborda el filme El santo de la espada va desde la llegada de San Martín a Argentina (1812) hasta su salida del país en 1824. Sin embargo, casi la mitad del filme está dedicado a los escasos meses en los que tuvo lugar la preparación del ejército en Cuyo, el cruce de los Andes y la batalla de Chacabuco, eventos en los que se centra el filme de Ipiña. 
él. El personaje ya no está investido del "valor moral inalcanzable" que le atribuyó Ricardo Rojas en El santo de la espada (1933), el libro que sirvió de principal fuente para el filme homónimo de Torre Nilsson (PALADINO; MARANGHELLO, 2010); sin embargo, no por ello deja de exhibir una enorme claridad en sus objetivos y en la estrategia para lograrlos, una gran determinación, y un enorme sentido del sacrificio y la rectitud. Habría que llamar la atención, también, sobre la manera reiterada con la que durante el filme se muestra a San Martín frente a espejos descascados, sucios o mal iluminados, como si el filme buscase que la representación del general asumiese cierto nivel -bastante tímido- de autoconciencia.

El filme de Leandro Ipiña no ahonda en la vida privada de San Martín, como sí lo hace el de Torre Nilsson donde la relación con su mujer ocupa buena parte de la trama y sirve como contrapeso romántico de las batallas, inscribiendo la historia dentro de una matriz melodramática. Remedios de Escalada y la hija de San Martín solo aparecen en una breve escena al principio del filme, que parece destinada a ahondar en la presentación del personaje y a contraponer, la unión de su familia patriota a la división de la familia realista de Manuel Corvalán, que queda en evidencia en la escena inmediatamente anterior. Ipiña tampoco entrega ningún antecedente biográfico de San Martín, pero lo caracteriza con acento español, algo que no es explicado en el filme, pero que lleva al público a recordar los largos años que San Martín, hijo de españoles, pasó en la Península Ibérica. Desde el punto de vista de la caracterización, este es uno de los aspectos más llamativos de la propuesta de Revolución: el cruce de los Andes y supone una relectura que cuestiona la identidad de quien tradicionalmente es considerado el "padre de la patria".

Es interesante analizar otros aspectos que no tienen relación directa ni con la vida privada de San Martín ni con sus características externas, sino con su ideología. El filme de Torre Nilsson relega al olvido que San Martín era masón, un aspecto fundamental dentro de su actividad política y militar. El de Ipiña, en cambio, muestra una consecuencia de su pertenencia a la masonería: al principio del filme, en una escena en la que habla con Fray Félix Aldao sobre la misión del religioso en el ejército, queda claro el distanciamiento del general con la Iglesia Católica. Sin embargo, el origen ideológico de sus recelos hacía la religión católica no es explicitado, quedando a cargo del público suponer las causas.

Evacuada la masonería como uno de los principales fundamentos ideológicos del personaje, lo que resta es un héroe que defiende la libertad y que está convencido de la igualdad de los hombres. Como se ve, se trata de dos valores bastante universalistas que por sí solos podrían acercarlo tanto a idearios de la izquierda como del liberalismo. 
Con todo, el fuerte sentido de la camaradería que desarrolla con los soldados rasos, su elogio al pueblo de Cuyo como motor de la lucha, su total ausencia de prejuicios raciales y su exaltada crítica de los privilegios de clase -“Usted no es hijo de nadie", le dice a Corvalán, "aquí se sube o se baja por mérito propio"- establecen un vínculo interclasista entre el líder y sus hombres, que se basa en una mezcla de afecto, admiración y fraternidad, pero que en ningún momento llevará a un cuestionamiento de las jerarquías. El líder trata como camaradas a sus hombres, y además conoce, asume y reivindica los intereses de estos; sin embargo, no está en duda la subordinación de los segundos al primero. En ese sentido, no parece improcedente plantear que la relación entre San Martín y sus soldados es similar a la relación entre Juan Domingo Perón y los descamisados promovida por la propaganda de los primeros gobiernos peronistas.

\section{Soldados desconocidos}

Uno de los aspectos más reiterados en la película es que la idea de estado-nación aún no había sido plenamente desarrollada en 1817. En concordancia con lo anterior, hay una ausencia bastante notable de símbolos patrios a lo largo del filme, que quedan reducidos a la aparición breve, en pocas escenas, de las banderas de Argentina y Chile. Hay que resaltar que se muestran versiones anteriores a las banderas que utilizan en la actualidad ambos países, lo que supone optar por reforzar el distanciamiento con esos emblemas. Es exactamente la opción opuesta a la que siguieron a comienzos de los años 1970 los filmes Bajo el signo de la patria (René Mugica, 1971) y El santo de la espada donde la bandera argentina y los colores azul y celeste son reiteradamente presentados, es más, el primero de ellos, sobre Manuel Belgrano, hace referencia explícita a la bandera en su título.

Esa distancia con la idea de estado-nacional es abordada explícitamente por el viejo Corvalán, como si el filme quisiera dejarla bien clara para el espectador, en un esfuerzo didáctico. Pero también, como si quisiera mostrarse que la memoria subjetiva de la experiencia vivida pone en jaque las versiones teleológicas de la historia. Hay que destacar que la revisión de la idea de nación parte, en el filme, desde un relato subjetivo. Un tipo de discurso que según Gustavo Aprea, ha venido siendo reivindicado por el cine histórico argentino, dejando en claro "la dificultad para construir una versión omnisciente, lineal y objetiva del pasado" (2012, p. 11).

La pugna entre historia oficial y memoria subjetiva estalla en torno al concepto de nación hacia el final del primer tercio del filme. El periodista le pregunta a Corvalán con tono solemne: “¿Cómo definiría 


\section{$\gamma_{\text {Rizoma }}$}

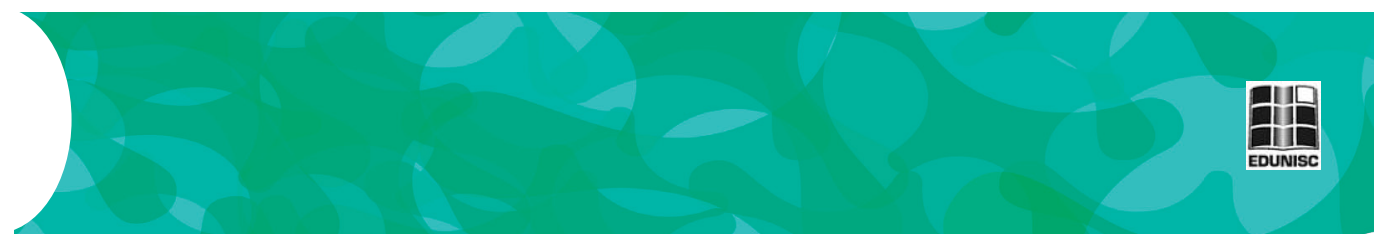

al padre de la patria?”, a lo que el anciano retruca: “¿Qué es para usted la patria?". El reportero, levemente incómodo, se hace repetir la pregunta, a lo lejos comienzan a sonar unas campanas, sutil elemento sonoro para destacar la importancia de la pregunta. El periodista rehúye la vista y responde con una risa nerviosa: "Bueno, la patria es el territorio”. El anciano le responde: “¿Padre de qué patria? ¿De la que ustedes llaman la Argentina? ¿De lo que fue el Reino de Chile? ¿De Perú? ¿De todas juntas?’. Durante el diálogo, el montaje de plano y contra-plano permite mostrar la creciente sorpresa del entrevistador. Para rematar la idea, Corvalán añade: "Sí, cuando cruzamos éramos la mitad chilenos y la mitad de Las Provincias Unidas".

Esa idea es reiterada constantemente a lo largo de todo el filme, principalmente en las escenas que transcurren en el campamento del ejército. La tropa es multinacional, está compuesta eminentemente por hombres de estrato popular, procedentes de diferentes lugares de las Provincias Unidas y por chilenos, así como por algunos soldados y oficiales cuyo acento evoca a los ejércitos colombianos y venezolanos de Bolívar y Sucre. Más interesante aún es su multietnicidad, en su mayoría son mestizos o indígenas, con un bajísimo número de blancos y uno significativo de afrodescendientes. Es más, la presencia de soldados negros, es uno de los elementos que más se repite visualmente en los planos generales y de conjunto del ejército. No solo se trata de soldados rasos, también hay sargentos, uno de los cuales juega al ajedrez con San Martín, en una larga escena en la que el general y él muestran un elevado sentido de la camaradería -San Martín llega a llamarlo "hermano"-, a pesar de las diferencias de rango.

Es perceptible que Revolución: el cruce de los Andes toma posición en un debate público que había ganado peso en Argentina en el momento en que se producía el filme: la necesidad de reconocer los orígenes africanos de la sociedad argentina y la participación de afrodescendientes en la independencia. Al respecto, el gobierno de Cristina Kirchner había comenzado a desarrollar políticas públicas destinadas al reconocimiento de los colectivos de afroargentinos, como la inclusión en el censo, la ley 28.852 que instituyó el día de los afroargentinos y la cultura afro (2014) y la publicación por la Secretaría de Derechos Humanos del estudio "Argentina, Raíces Afro: visibilidad, reconocimiento y derechos" (2014).

Hay que destacar que el filme no solo busca mostrar la diversidad étnica de la tropa, sino que también la ausencia de prejuicios raciales entre los soldados y un cierto espíritu de hermandad ${ }^{8}$. Esa tropa popular, plurinacional y multiétnica es propuesta como origen de la independencia latinoamericana y de una comunidad que solo posteriormente se dividirá en las comunidades imaginadas de las naciones latinoamericanas. El discurso del filme, al igual que el viejo
Con todo, esa horizontalidad tiene sus límites, pues los dos personajes principales, San Martín y Corvalán, son interpretados por actores blancos. 


\section{$\gamma_{\text {Rizoma }}$}

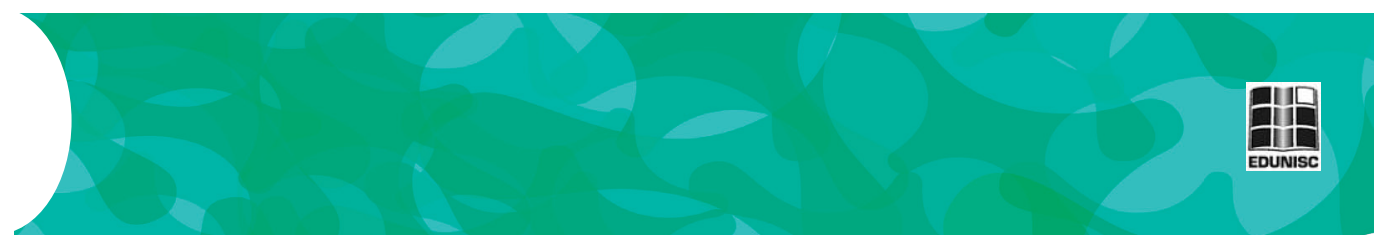

Corvalán, sostiene que la construcción de la nación es posterior a la independencia. Sin embargo, la noción - ciertamente idílica - de una hermandad entre pueblos y etnias latinoamericanos es propuesta como concomitante con la liberación del colonialismo. Dentro de esa comunidad proto nacional que antecede a la cristalización de la idea de nación, hay espacio para individuos que serán posteriormente excluidos por el estado-nación: el indígena y el negro.

La diversidad de esa comunidad en términos de etnia y procedencia contrasta con la uniformidad de su origen social: la inmensa mayoría de ellos son campesinos o proceden de las clases populares urbanas. La burguesía está prácticamente ausente del relato y, con ello, de la memoria que se propone de la independencia. Aparte de algunos personajes que aparecen en breves escenas, como Remedios de Escalada, la familia Corvalán y algunos oficiales, las dos grandes excepciones a lo anterior son José de San Martín y Manuel Corvalán, ambos de origen burgués. Sin embargo, en el primer caso estamos frente a alguien que aboga firmemente por la igualdad, mientras que el segundo personaje al romper con su padre (burgués y, sintomáticamente, realista) vive un proceso de desclasamiento, pues abandona los privilegios de la burguesía y termina como soldado raso. La narración se encarga de dejar en claro que no recuperará esa condición social inicial, al mostrarlo ya viejo, en una humilde pensión, y con dificultades para pagar el alquiler.

El pueblo "motor" es también pueblo "olvidado" por la historia oficial. La idea de ese olvido, que el filme vendría a desenterrar mediante el rescate de una hipotética memoria oral y popular, recorre todo el filme, pero se presenta con más fuerza en las últimas escenas. El periodista quiere hacer un daguerrotipo de Corvalán, para ilustrar el periódico en el que saldrá el reportaje; sin embargo, el anciano se niega a salir solo y llama a la comunidad para que esté presente también en la foto - una manera de reforzar la idea del colectivo y de la memoria popular. Mientras posan, Corvalán se pone a hablar y a moverse, a pesar de las advertencias del periodista. La siguiente imagen nos muestra el daguerrotipo, en el que Corvalán sale rodeado de sus vecinos, pero su rostro, como consecuencia de su movimiento, aparece totalmente borrado. La desaparición de las facciones que servirían para identificar a ese antiguo soldado es un tropo evidente del olvido en el que ha caído el personaje, pero la imagen puede interpretarse también como la unificación de ese personaje y tantos otros hombres y mujeres anónimos y olvidados que combatieron por la Independencia, una idea que se encarga de transmitir el titular del periódico en el que sale el daguerrotipo: "Los que hicieron la patria". En lo que constituye una nueva reiteración las ideas principales del filme, los créditos incluyen la canción "Soldado desconocido", con los versos "es cosa fiera que nos manden al olvido como soldados desconocidos". 


\section{$\gamma_{\text {Rizoma }}$}

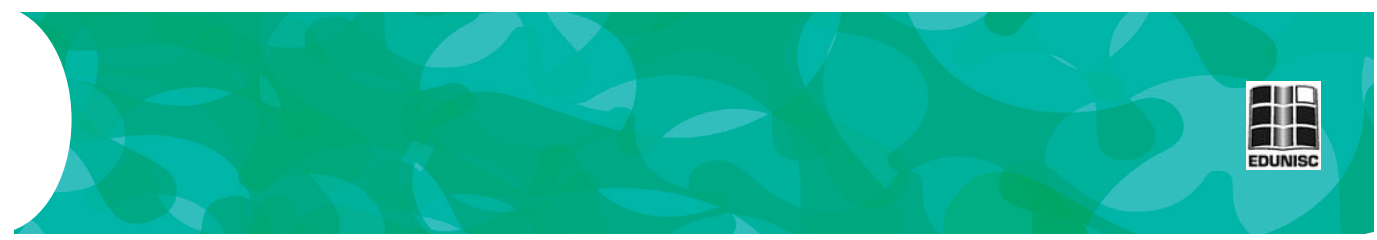

\section{La libertad y el colonialismo}

El discurso de la libertad, que se enarbola constantemente como justificación y objetivo de la lucha, es otro de los pilares sobre los que se construye el relato de Revolución: el cruce de los Andes. La palabra "libertad" desde el prólogo del largometraje en adelante substituye totalmente al concepto de "independencia". De la misma manera, la noción de "revolución" evocada en el título substituye a la de "guerra", este último concepto es visto en el filme como una consecuencia indeseable, pero necesaria, para el fin del colonialismo. En ese sentido, el filme evita conscientemente la apología del belicismo, representando la guerra como algo cruel y a la vez prosaico, alejado de cualquier tipo de honor y pompa militar. Así lo muestran algunas escenas de las secuencias de la batalla de Chacabuco, con apunalamientos por la espalda, y con la desesperación, los chillidos y la desorientación de algunos soldados. Pero el discurso antibelicista aparece sobre todo en boca de Fray Félix Aldao, un sacerdote que intenta aleccionar a Manuel Corvalán en el campamento militar:

\footnotetext{
La guerra no es lo que dicen los libros. Ni son cálculos ni números ni tácticas ni medallas, la guerra es barro, humo, olor a sangre, mierda [...]. La guerra es absurda porque arrastra a un muchacho como usted a pelear con todo el futuro por delante, pero parece que es el único camino hoy, ¿no?
}

Los deslizamientos semánticos que van de la independencia a la liberación y de la guerra a la revolución ya están presentes en el prólogo del filme, donde se aprecia, también, el discurso latinoamericanista evocado en la sección anterior. Una voz over con tono marcadamente didáctico ofrece resumidamente una contextualización histórica mientras la imagen muestra un mapa de Sudamérica que va progresivamente ampliándose para mostrar las zonas dominadas por los realistas y los independentistas hacia 1815. No existen fronteras claras entre los virreinatos españoles ni tampoco entre estos y las colonias portuguesas y las zonas de influencia realista e independentista tienen límites difusos. Por su parte, las palabras utilizadas por la voz over hacen hincapié en una interpretación del proceso como latinoamericanista, revolucionario y libertador:

Cuando España se desmorona ante Napoleón, sus ecos llegan hasta las colonias americanas. El fin del colonialismo ya no es un sueño para los pueblos de América que casi al unísono se levantan y forman sus propios gobiernos. Pero la revolución solo puede imponerse de una sola (sic) forma, con la guerra. La contrarrevolución no tarda en llegar y restaurar aquel viejo sistema a fuerza de sangre y fuego. Para 1815 solo las Provincias Unidas del Río de 

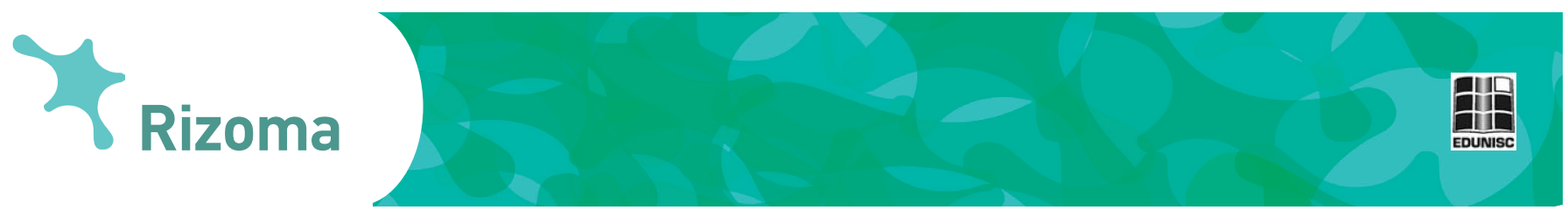

la Plata quedan en pie. Desde Cuyo, una zona aislada y pobre, José Francisco de San Martín, crea, instruye y se pone al frente de un ejército de 5200 hombres para cruzar los Andes y liberar Chile como primer paso de un plan mayor, la libertad de todo un continente. (Énfasis mío).

El concepto de la libertad es evocado en varias ocasiones por múltiples personajes como, Fray Félix Aldao, el sargento Blanco, Manuel Corvalán y José de San Martín. En el caso de este último, la arenga que dirige al ejército antes de Chacabuco incluye la famosa frase: "Seamos libres y lo demás no importa nada", que tiene como fuente histórica la orden general del 27 de julio de 18199. Todo el discurso que precede a la batalla gira en torno a la misma idea: la construcción de una sociedad libre. Pero es interesante constatar que para el San Martín representado en el filme, esa libertad es concebida como un imperativo a partir del cual se construye también la igualdad social. Ese primer valor termina siendo prerrequisito del segundo:

Todos y cada uno de ustedes lleva consigo lo más importante, la libertad [...]. Nuestros hijos y los hijos de nuestros hijos recordarán este momento con orgullo porque les dejaremos una tierra digna de ser vivida donde puedan sembrar, crecer y prosperar libres de toda cadena, donde cada hombre pueda decidir su destino sin importar su color, su linaje, su procedencia ni qué carajo.

La noción de la libertad es a tal punto omnipresente que uno de los dos realistas individualizados en el filme, Fray Bernardo García, encara a Corvalán, precisamente cuestionando la libertad por la que lucha: "Ustedes se llenan la boca de palabras que no entienden: la libertad. ¿Y qué sabe usted de la libertad?”. La pregunta no es respondida por el adolescente Corvalán, pero el filme no deja esa cuestión abierta, sino que hace que sea el héroe quien la responda en una de las últimas escenas antes de la batalla de Chacabuco. Se trata de la partida de ajedrez con el sargento negro a la que me he referido en la sección anterior. Estructurada a partir de un campo contra-campo entre los dos personajes, la cámara realiza un ligero zoom-in tanto desde la perspectiva de ambos personajes, como forma de intensificar el efecto emotivo de las palabras de San Martín:

Peleamos porque es nuestro destino como hombres en este momento de la historia. Bello sería no tener que hacerlo. La libertad puede llegar a ser solo una palabra. Pero no peleamos por cualquier libertad, creo que hay algo más. Estamos intentando algo grande, sargento. Un profundísimo anhelo que todos los humanos tenemos en algún lugar. ¿Vos llegás a comprenderlo, hermano?
9 Los guionistas del filme, Leandro Ipiña y Andrés Maino, seleccionaron algunas de sus cartas y bandos militares para construir parte de los diálogos de San Martín. La misma frase citada aparece también en El santo de la espada, en las escenas de preparación del ejército de los Andes. 


\section{$\gamma_{\text {Rizoma }}$}

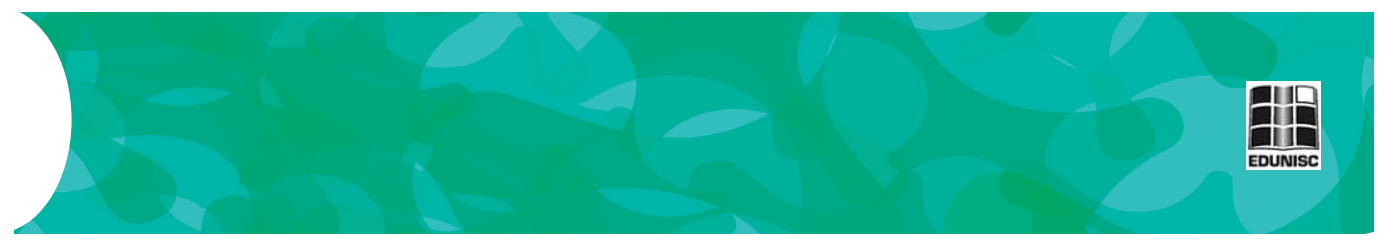

El cambio de registro en la última frase, donde San Martín pasa a utilizar el voseo característico argentino, en lugar del formal "usted", así como el empleo de la palabra "hermano", le otorgan una mayor proximidad y complicidad a sus palabras. El diálogo reitera la idea central de la libertad asociada a la igualdad, pues la lucha por la libertad "hermana" (iguala) a los hombres con independencia de su raza u origen. También se reitera la noción de la violencia como una necesidad, como la única opción en ese momento histórico para lograr un fin mayor. Sin embargo, no deja de llamar la atención la vaguedad e indefinición del discurso del héroe, precisamente en el momento del filme en el que se esperaría que quedase claro en qué consiste esa libertad por la que se lucha. San Martín establece ese problema: la libertad puede llegar a ser solo una palabra, pero a la hora de explicar lo que entiende por libertad opta por la ambigüedad, no es un concepto, sino un "anhelo", "algo grande", que todos llevamos dentro, en "algún lugar". El filme opta por una concepción emotiva y sentimental de la libertad, en lugar de intentar una construcción conceptual más rigurosa, a pesar de ser uno los pilares sobre los que funda todo su relato.

Pese a la importancia atribuida a la lucha por la libertad, una de las cuestiones más curiosas del filme es la práctica ausencia de referencias a la metrópoli colonial. España casi no es mencionada en el filme y los defensores de la corona son definidos como "realistas", "maturrangos" o "godos" - término peyorativo de la época-, pero nunca como españoles. Todos los soldados del ejército español son mestizos latinoamericanos y únicamente dos personajes realistas hablan a lo largo de todo el filme, uno de ellos es el sacerdote criollo Fray Bernardo García, el otro es el padre de Manuel Corvalán que solo aparece al comienzo del filme, en una escena de poco más de dos minutos. Su acento peninsular lleva a deducir que es español, el único de todo el filme. Con la excepción de esos dos personajes secundarios, los antagonistas del Ejército Libertador son representados como una masa indiferenciada y nunca vemos a sus líderes.

La invisibilidad de los españoles sitúa a la guerra de independencia más como una lucha contra el absolutismo o una contienda entre latinoamericanos que como un conflicto entre la metrópoli y sus colonias. De acuerdo con Iciar Recalde (2011, p. 2): "Revolución, el cruce de los Andes permite vislumbrar un proceso revolucionario, no como un movimiento segregacionista, sino como una extensión de los estallidos revolucionarios tanto en el resto del continente americano como en España desde 1808, todos estos, estallidos democráticos contra el absolutismo". Esa invisibilidad de la metrópoli colonial tiene como contrapartida la gran atención que se le da a un aspecto que revela la fuerte relación biográfica y cultural de San Martín con 


\section{$\gamma_{\text {Rizoma }}$}

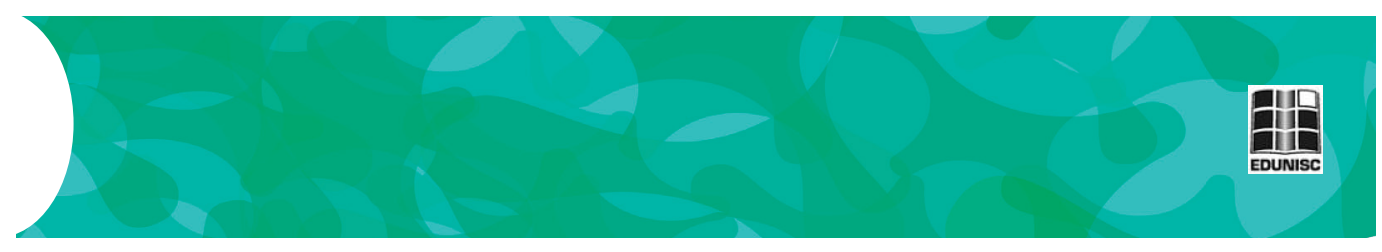

España, pues el actor Rodrigo de la Serna adopta un acento peninsular para interpretar al prócer argentino. Por paradójico que pueda parecer, el principal líder de la independencia es también uno de los personajes más españoles de todo el filme.

Esa dinámica de invisibilidad del antagonista español y visibilidad de rasgos españoles en San Martín probablemente esté relacionada con el hecho de que Revolución: el cruce de los Andes forme parte de la serie fílmica Libertadores, coproducida por Televisión Española, Lusa Filmes y Wanda Filmes ${ }^{10}$. El análisis sobre la invisibilidad de la metrópoli unida al estudio de las fuentes de financiación hacen necesario relativizar la conclusión de que el filme es única y exclusivamente kirchnerista, pues existen en su proceso de producción y realización negociaciones con otros agentes culturales y otros proyectos ideológicos, en este caso, las políticas culturales de la televisión pública española.

\section{Reflexiones finales}

De acuerdo con Le Goff (2013, p. 390): "Volverse señores de la memoria y del olvido es una de las grandes preocupaciones de las clases, los grupos, los individuos que dominaron y dominan las sociedades históricas". Para el historiador francés, el control sobre la memoria colectiva es un tipo de poder, del que forma parte también la selección de lo que será olvidado. La memoria y el olvido son dos polaridades de la misma cuestión, asociadas a un intento de perpetuación de discursos específicos sobre el pasado, es decir, a la perpetuación de una determinada mentalidad y, más importante aún, de una iconosfera asociada a ella. Como se ha visto, el rescate del olvido de una memoria popular oral que habría sido dejada de lado por la historia oficial, es uno de los objetivos centrales del ejercicio de revisionismo histórico emprendido en Revolución: el cruce de los Andes. Sin embargo, esa operación no tiene como finalidad tan solo ofrecer un documento audiovisual que reinterpreta el peso de las masas olvidadas en las luchas por la independencia, sino que busca crear un monumento sobre ellas. $\mathrm{Al}$ analizar el filme como una fuente para entender los discursos sobre la independencia surgidos en Argentina en el contexto del bicentenario, es preciso tener en cuenta que estamos ante un documento-monumento, en el sentido que le otorga Le Goff a esa duplicidad:

(El documento) es un producto de la sociedad que lo fabricó según las relaciones de fuerzas que detentaban allí el poder. Solo el análisis del documento en tanto monumento permite a la memoria colectiva recuperarlo y al historiador usarlo científicamente, es decir, con pleno conocimiento de causa. (2013, p. 495).
10 Esa ambigüedad está presente también en el filme La Redota donde el protagonista, es un espía español, enviado a Uruguay por el gobierno de las Provincias Unidas (no por España) para matar a Artigas.

Sin embargo, el espía se siente fascinado por Artigas, seducido por su discurso y su relación con el pueblo. El actor, Rodolfo Sancho, que interpreta al espía, es hijo del productor Sancho Gracia. 


\section{$\gamma_{\text {Rizoma }}$}

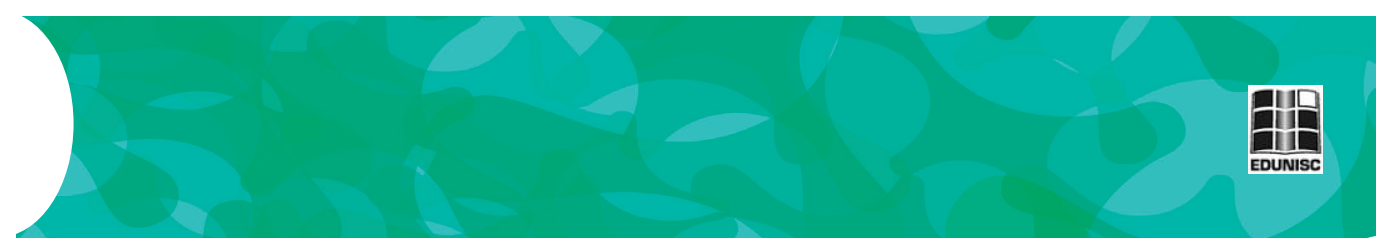

Esto es particularmente válido en el caso de los soldados anónimos, de los campesinos de Cuyo o de la población negra que gana una nueva dimensión en el filme, pasando del olvido a una centralidad monumental. Ellos son "los que hicieron la patria", tal y como reza el titular del periódico del filme, una frase que sirve de epitafio para el monumento al soldado desconocido que el filme construye. La afirmación es válida también para la caracterización de San Martín, pues aunque se ofrece una representación del héroe, aparentemente lejana de los bronces ecuestres, el filme acaba por convertirlo en la reserva moral de un ideario político que promueve la creencia de que existiría una sintonía entre los deseos e intereses de la masa y las acciones de un líder.

\section{Referencias}

APREA, Gustavo. Cine histórico argentino contemporáneo: una nueva manera de relacionarse con el pasado. In: ROMANO, Silvia; ZANOTTO, Matías (eds). Actas del III Congreso de AsAECA Córdoba, 2012. Córdoba: Asociación Argentina de Estudios de Cine y Audiovisual (AsAECA), 2012. Disponible en: http://www. asaeca.org/aactas/aprea_gustavo_-_ponencia.pdf. Acceso en: 10 ago. 2018.

CARROLL, Noël. Ficção, não ficção e o cinema da asserção pressuposta: uma análise conceitual. In: RAMOS, Fernão Pessoa (org). Teoria contemporânea do cinema: documentário e narratividade ficcional. São Paulo: Senac, 2005. p. 69-104.

DEL VALLE DÁVILA, Ignacio. Un monument en 24 images par seconde: El santo de la espada. IdeAs, n. 7, 2016. Disponible en: http://ideas.revues.org/1435 Acceso en: 10 ago. 2018.

ERAUSQUIN, Estela. Héroes de película: el mito de los héroes en el cine argentino. Buenos Aires: Biblos, 2008.

LE GOFF, Jacques. História e memória. Campinas: Editora da Unicamp, 2013.

LUSNICH, Ana Laura. El cine criollista-histórico. In: ESPAÑA, Claudio (org). Cine argentino, modernidad y vanguardias (19571983). Buenos Aires: Fondo Nacional de las Artes, 2005. p. 410-419.

MENESES, Ulpiano. Fontes visuais, cultura visual, história visual: 

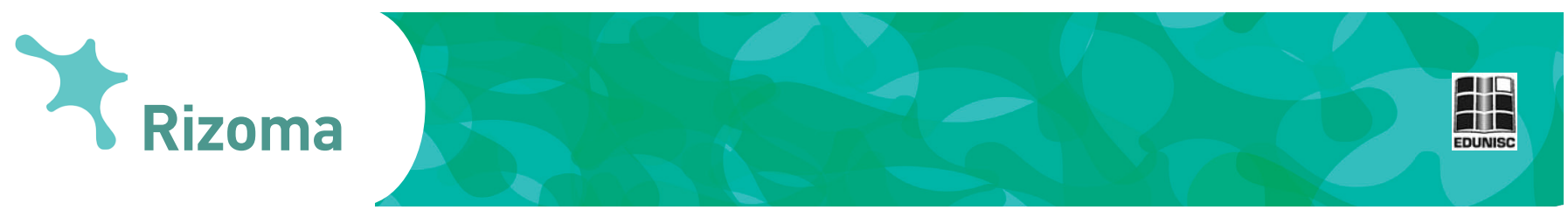

balanço provisório, propostas cautelares. Revista Brasileira de História, São Paulo, v. 23, n. 45, p. 11-36, 2003.

PALADINO, Diana; MARANGHELLO, César. San Martín en el cine: representaciones del siglo XX. Cinémas d'Amérique latine, n. 18, p. 28-40, 2010.

RECALDE, Iciar. Cine y revisionismo histórico: la cuestión espanola en el filme Revolución, el cruce de los Andes de Leandro Ipiña. In: CORBELLINI, Natalia (ed). Diálogos Transatlánticos: memorias del II Congreso Internacional de Literatura y Cultura Espanola Contemporáneas. La Plata: Mercado Editorial, 2011.

TAL, Tzvi. El Kruce de los Andes: memoria de San Martín y discurso político en Revolución (Ipiña, 2010). Cuaderno 52, p. 241-253, 2015.

\author{
Avaliadores: \\ Sergio Gadini \\ Demétrio Soster \\ Rosangela Fachel
}

